\title{
Evaluation of spinal cord blood flow during prostaglandin E1-induced hypotension with power Doppler ultrasonography
}

\author{
T Tsuji*,1, Y Matsuyama ${ }^{1}, \mathrm{~K}$ Sato $^{2}$ and $\mathrm{H}$ Iwata $^{1}$ \\ ${ }^{1}$ Department of Orthopedic Surgery, Nagoya University School of Medicine, Nagoya, Japan; ${ }^{2}$ Department of \\ Orthopedic Surgery, Nagoya Daini Red Cross Hospital, Nagoya, Japan
}

\begin{abstract}
Study design: Intraoperative power Doppler ultrasonography was used to evaluate the spinal cord blood flow in cervical spondylotic myelopathy patients during hypotensive anesthesia. Objective: To evaluate the effect of prostaglandin E1 (PGE1) induced hypotension on spinal cord blood flow (SBF) during spinal surgery.

Summary and background data: Hypotension is frequently induced to decrease blood loss during surgery and to diminish the need for blood transfusion. Prostaglandin E1 (PGE1) is reported to maintain cerebral, liver, and renal blood flow during surgery. However, there are few reports on spinal cord blood flow.

Methods: Eleven patients underwent laminoplasty for cervical spondylotic myelopathy. After a French door type laminoplasty was carried out, hypotension was induced with PGE1. Before and during hypotension, we evaluated blood flow in the anterior spinal cord artery by determining the pulsatility index (PI) and resistance index (RI) using power Doppler ultrasonography.

Results: Before hypotension, the mean blood pressure was $80 \mathrm{mmHg}$. The blood pressure decreased to $60 \mathrm{mmHg}$ using PGE1 $(P<0.01)$, although the PI and RI were significantly higher than before hypotension (PI, $P=0.0076 \mathrm{RI}, P=0.02$ ).

Conclusion: The pulsatility and resistance indices during hypotension were significantly higher than before hypotension, suggesting that the autoregulation of the anterior spinal cord artery and anterior spinal cord blood flow were maintained with hypotension using PGE1. Prostaglandin E1 may be a useful drug for hypotensive anesthesia in spinal surgery.

Spinal Cord (2001) 39, $31-36$
\end{abstract}

Keywords: spinal cord blood flow; Prostaglandin E1; power Doppler ultrasonography

\section{Introduction}

Induced hypotension is frequently employed to decrease blood loss during surgery and to diminish the need for and risk of blood transfusion. ${ }^{1,2}$ The characteristics of an ideal hypotensive agent include easy administration, predictability with anesthetic agents, and lack of toxic side effects while maintaining adequate perfusion of the vital organs. ${ }^{3}$ A variety of intravenous vasodilating agents have been used. However, some side effects, including increased intracranial pressure ${ }^{4}$ and tachyphylaxis, ${ }^{5}$ have been reported.

Prostaglandin E1 (PGE) is reported to maintain circulation of the vital organs, including the brain, liver and kidney, during surgery. ${ }^{3}$ However, there are few reports about spinal cord blood flow. Previous studies of spinal cord blood flow have used methods such as the heat clearance method, ${ }^{6}$ hydrogen gas clearance method, ${ }^{7}$ and a laser-Doppler meter, ${ }^{8}$ so the

*Correspondence: T Tsuji, Department of Orthopedic Surgery, Nagoya University School of Medicine, 65 Tsuruma-cho, Showaku, Nagoya, 466-8550, Japan results were not clear or the methods not suitable for human beings. Recently, intraoperative ultrasonography has been developed, ${ }^{9}$ enabling visualization of the anterior spinal cord artery, which is the main artery to the spinal cord, in real time. We evaluated the effect of prostaglandin E1 (PGE1), which induces hypotension, on spinal cord blood flow (SBF) using power Doppler ultrasonography during spinal surgery on patients with cervical spondylotic myelopathy.

\section{Methods}

Informed consent was obtained from each patient. This prospective study included 11 patients (mean age 63.4 years old) undergoing laminoplasty from $\mathrm{C} 3$ to $\mathrm{C} 7$ for cervical myelopathy in the prone position. No patient had hepatic or renal dysfunction. For premedication, $50 \mathrm{mg}$ hydroxydine were administered intramuscularly $1 \mathrm{~h}$ before surgery. Anesthesia was induced with $0.1 \mathrm{mg}$ fentanyl and $1.0-2.0 \mathrm{mg} / \mathrm{kg}$ propofol, and $0.1 \mathrm{mg} / \mathrm{kg}$ vecuronium bromide was given to facilitate 
tracheal intubation. Anesthesia was maintained with $3 \mathrm{mg} / \mathrm{kg} / \mathrm{h}$ propofol. Blood pressure was monitored continuously though a Swan-Ganz catheter. Rectal temperature was monitored and maintained at $37^{\circ} \mathrm{C}$ with a circulating water heating mat. ${ }^{3}$ With the patient in the prone position, a French door type laminoplasty was performed at the cervical spine. After the lamina arch was opened, the power Doppler ultrasonography probe (GE Yokogawa Medical Systems, Ltd., Tokyo, Japan) was placed on the dura mater using the water immersion method. ${ }^{9}$ This visualized the anterior spinal artery so we could measure its blood flow.

The power Doppler technique produces an image whose characteristics are very similar to X-ray angiography. ${ }^{9,10}$ All forms of ultrasound-based imaging of red blood cells are derived from the echo signal that is received from them in response to the transmitted ultrasound beam. The essential characteristics of this signal are its frequency and its amplitude, which are influenced by fundamentally different properties of the red blood cells. The frequency shift is determined by the movement of red blood cells, whereas the amplitude is governed by the amount of moving blood present within the volume sampled by the ultrasound beam. ${ }^{11}$

The fast Fourier transformation waveforms of blood flow signals obtained with power Doppler ultrasonography were analyzed. Pulsatile flow wave signals were received, and maximal, minimal, and mean velocity (Vmax, Vmin, and Vmean, respectively) were determined. To avoid the effects of velocity, we used the pulsatility index $(\mathrm{PI})=(\mathrm{Vmax}-\mathrm{Vmin}) /$ Vmean and resistance index $(\mathrm{RI})=(\mathrm{Vmax}-\mathrm{Vmin})$ $\mathrm{Vmax}^{10}$ (Figure 1). These indices indicate vascular impedance. Impedance means vascular resistance in the anterior spinal artery and an increase in these indices suggests increased vasotonia.

These indices were measured six times before and during hypotension. Six control measurements were made before starting hypotension. PGE1 was administered initially at $0.1 \mu \mathrm{g} / \mathrm{kg} / \mathrm{min}$ intravenously and the dose was adjusted to maintain a mean arterial blood pressure (MAP) of about $60 \mathrm{mmHg}$. When the MAP was about $60 \mathrm{mmHg}$, PI and RI were measured six times before hypotension was discontinued.

The data analysis was performed with StatView 4.02 software (ABACUS, Berkeley, CA, USA) on a personal computer. All values are expressed as the mean \pm standard deviation (SD). The Spearman rank correlation coefficient was used to determine correlations. The Wilcoxon signed rank test was used to compare values before and during hypotension. A $P$ value $<0.05$ was considered significant.

\section{Results}

Before hypotension, mean arterial blood pressure was $84 \pm 12 \mathrm{mmHg}$, the pulsatility index was $1.097 \pm 0.17$, and the resistance index was $0.650 \pm 0.057$. During hypotension, mean arterial blood pressure was

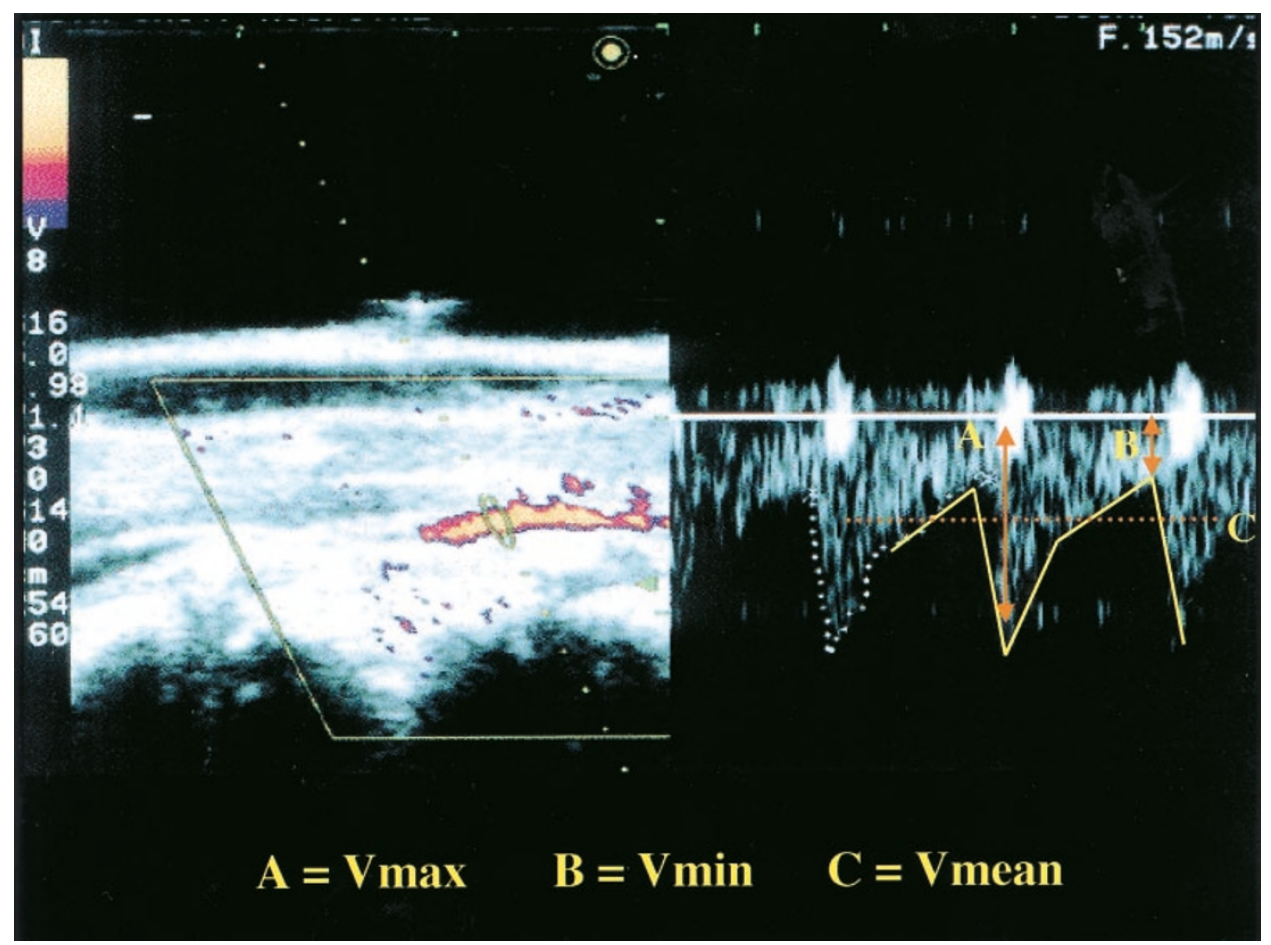

Figure 1 On the left hand of the figure, the anterior spinal cord artery is visible with power Doppler ultrasonography. On the right hand of the figure, the fast Fourier transformation waveforms of blood flow signals obtained with power Doppler urtrasonography. Pulsatility Index $(\mathrm{PI})=(\mathrm{V} \max -\mathrm{Vmin}) / \mathrm{Vmean}$; Resistance Index $(\mathrm{RI})=(\mathrm{V} \max -\mathrm{V} \min ) / \mathrm{V} \max$ 
$63 \pm 7 \mathrm{mmHg}$, the pulsatility index was $1.201 \pm 0.23$, and the resistance index was $0.675 \pm 0.07$ (Figure $2 \mathrm{a}-$ c). The mean value from each patient is shown in Table 1. MAP during hypotension was significantly lower than before hypotension $(P<0.01)$. PI and RI during hypotension were significantly higher than before hypotension (PI, $P=0.0076 ; \quad$ RI, $P=0.02$ ). The differences in the values of PI and RI before during and post hypotension are given as \%PI and \% RI $(\% \mathrm{PI}=\mathrm{PI}$ during hypotension/PI before hypotension, $\% \mathrm{RI}=\mathrm{RI}$ during hypotension/RI before hypotension). The values of $\% \mathrm{PI}$ and $\% \mathrm{RI}$ were correlated with age $(\% \mathrm{PI}, r=0.43 ; \% \mathrm{RI}, r=0.50)$ (Figure 3a,b).

\section{Typical case}

A 44-year-old man presented with upper and lower extremity hypoesthesia and weakness. Physical examination revealed a spastic gait, with $4 / 5$ power, spasticity, and long tract signs in the lower extremities. The Japanese Orthopedic Association score was 6 out of 17. MRI revealed a compression mass lesion ventral to the spinal cord at C4-C7 (Figure 4). French door type laminoplasty was selected and performed with hypotensive anesthesia using PGE1 and intraoperative ultrasonography. After the lamina arch was opened, the power Doppler probe was positioned, enabling visualization of the anterior spinal artery and measurement of its blood flow (Figure 5). Before hypotension, MAP was $90 \pm 0.0 \mathrm{mmHg}$, PI was $1.25 \pm 0.19$, and RI was $0.729 \pm 0.05$. After PGE was given, MAP decreased to $63 \pm 3 \mathrm{mmHg}$, and PI and RI increased to $1.409 \pm 12$ and $0.735 \pm 0.03$, respectively.

\section{Discussion}

This study examined spinal cord blood flow in the anterior spinal cord artery during hypotensive anesthesia with PGE1. During spinal surgery, the major problems are bleeding and spinal cord perfusion. Abe et $a l^{12}$ reported that epidural blood flow did not change during hypotensive anesthesia using PGE1. They also made measurements with the dura open, and reported that the spinal cord blood flow did not change. ${ }^{3}$ However, they used a heat clearance blood flow meter, which cannot measure flow in a specific artery.

Many authors have reported that the spinal cord is supplied almost exclusively by the anterior spinal cord artery and that dysfunction of this artery causes spinal cord failure. ${ }^{13,14}$ Therefore, we measured flow in the anterior spinal cord artery to determine spinal cord blood flow. Using a laser-Doppler meter, Kodama et $a l^{8}$ reported that spinal cord blood flow increased after laminoplasty. However, this method also cannot measure flow in a specific artery. For this reason, our method using power Doppler ultrasonography is useful.

We showed that the pulsatility index (PI) and resistance index (RI) during hypotension were sig-
A

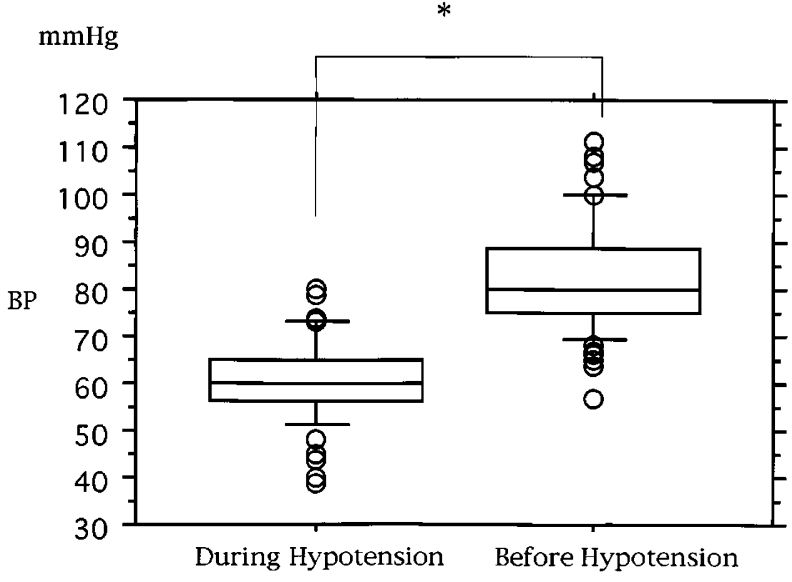

B

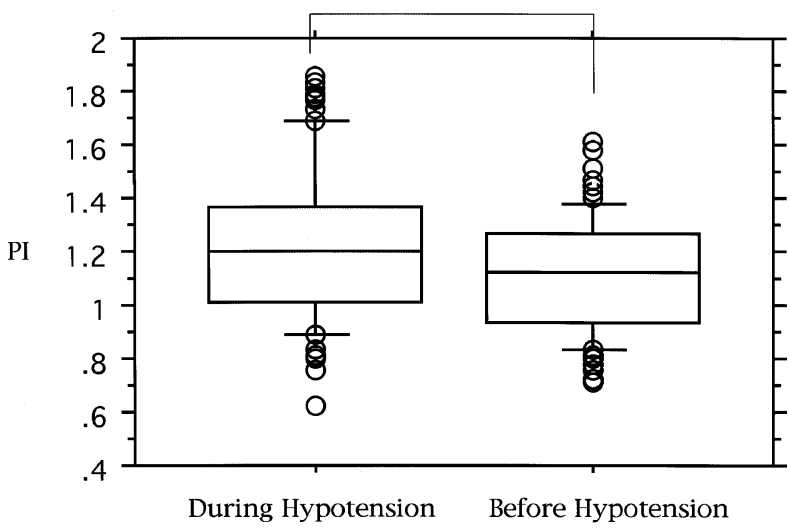

C

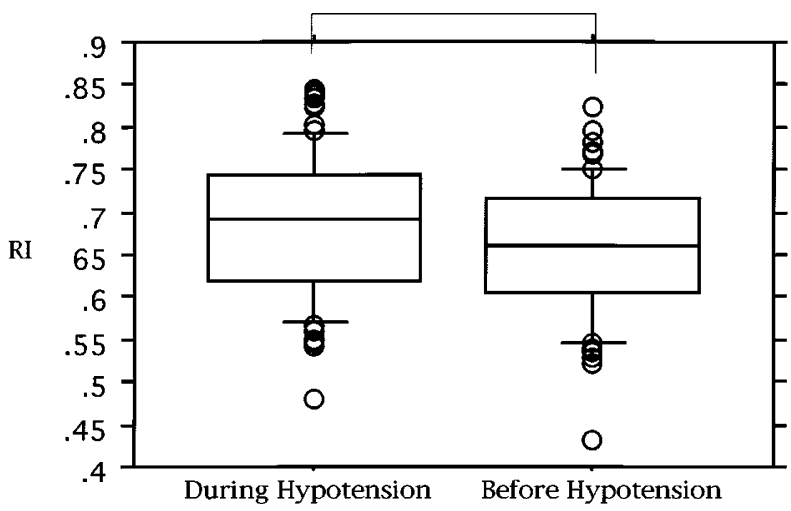

Figure 2 (a) Mean arterial blood pressure during PGE1 administration was significantly lower than before administration. $* P<0.01$. (b) PI during hypotension was significantly higher than before hypotension. ${ }^{*} P=0.0076$. (c) RI during hypotension was significantly higher than before hypotension. $* P=0.02$ 
Table 1

\begin{tabular}{|c|c|c|c|c|c|c|}
\hline Patients & B. $H-B P$ & B.H-PI & B. $H-R I$ & D. $H-B P$ & D.H-PI & $D . H-R I$ \\
\hline A & 90 & 1.25 & 0.729 & 63 & 1.409 & 0.735 \\
\hline B & 100 & 1.135 & 0.674 & 67 & 1.073 & 0.645 \\
\hline $\mathrm{C}$ & 69 & 0.902 & 0.571 & 61 & 0.995 & 0.597 \\
\hline $\mathrm{D}$ & 83 & 0.946 & 0.6 & 59 & 0.954 & 0.608 \\
\hline $\mathrm{E}$ & 77 & 1.269 & 0.703 & 73 & 1.414 & 0.764 \\
\hline $\mathrm{F}$ & 80 & 1.324 & 0.707 & 62 & 1.664 & 0.798 \\
\hline $\mathrm{G}$ & 79 & 1.11 & 0.63 & 50 & 1.28 & 0.687 \\
\hline $\mathrm{H}$ & 68 & 1.125 & 0.672 & 55 & 1.129 & 0.686 \\
\hline I & 86 & 1.098 & 0.671 & 62 & 1.208 & 0.677 \\
\hline $\mathrm{J}$ & 79 & 1.141 & 0.639 & 67 & 1.205 & 0.641 \\
\hline $\mathrm{K}$ & 108 & 0.769 & 0.554 & 72 & 0.885 & 0.588 \\
\hline Mean & $84 \pm 12$ & $1.1 \pm 0.17$ & $0.65 \pm 0.06$ & $63 \pm 7$ & $1.20 \pm 0.23$ & $0.68 \pm 0.07$ \\
\hline
\end{tabular}

B.H, before hypotensive anesthesia; D.H, during hypotensive anesthesia; BP, mean blood pressure; PH, pulsatility index; RI, resistance index

A

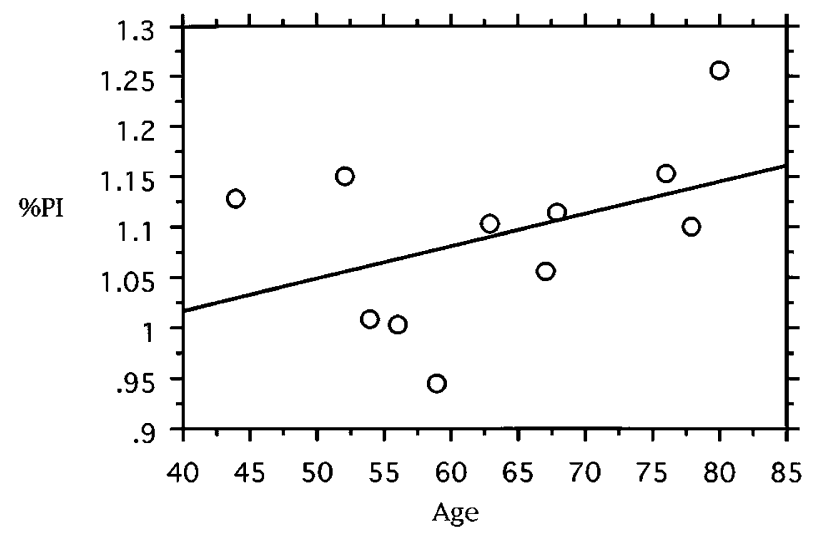

B

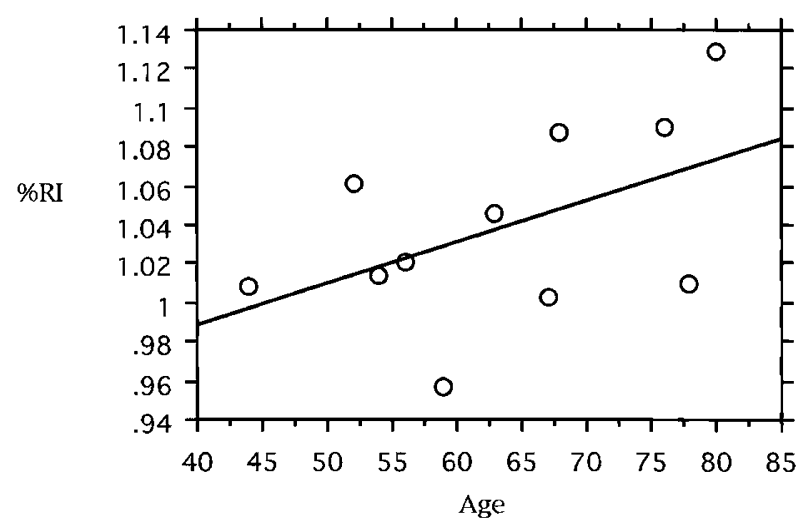

Figure 3 (a) The values of $\%$ PI were correlated with age. $r=0.43$. (b) The values of $\% \mathrm{RI}$ were correlated with age. $r=0.50$

nificantly higher than before hypotension. In considering the values of PI and RI, Sekizuka et $a l^{15}$ reported that in measurements of fetal circulation these indices increase in a telangion and decrease in an intermediate artery when blood flow increases. Several studies that

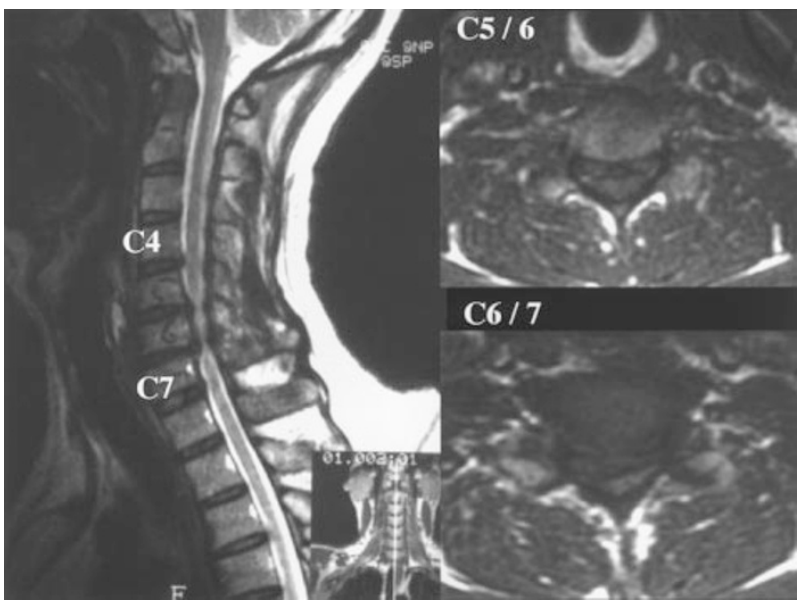

Figure 4 Before operation, MRI revealed a compression mass lesion ventral to the spinal cord at $\mathrm{C} 4-\mathrm{C} 7$

measured the blood flow of malignant tumors using power Doppler ultrasonography showed that blood flow in malignant tumors had a lower PI and RI than in benign tumors because of higher blood flow. ${ }^{10,16}$ The size of these arteries was almost intermediate. The anterior spinal cord artery is an arteriole with a diameter of about $0.5 \sim 1.0 \mathrm{~mm}$. In our study, there was a significant increase in PI and RI. These indices indicate vasotonia. Our results suggest that vasotonia of the anterior spinal artery increased, and autoregulation of spinal cord blood flow was maintained during hypotension. In consideration of these facts we also suggest that blood flow in the anterior spinal artery was maintained during PGE1 administration.

We used prostaglandin E1 in this study. PGE1, a natural product of many mammalian tissues, has been administered safely in humans. ${ }^{17}$ It produces profound relaxation of arteriolar vascular smooth muscle, and decreases vascular resistance in the renal, mesenteric, coronary, and pulmonary circulation. PGE1 reduces blood pressure by relaxing vascular smooth muscle, 
A

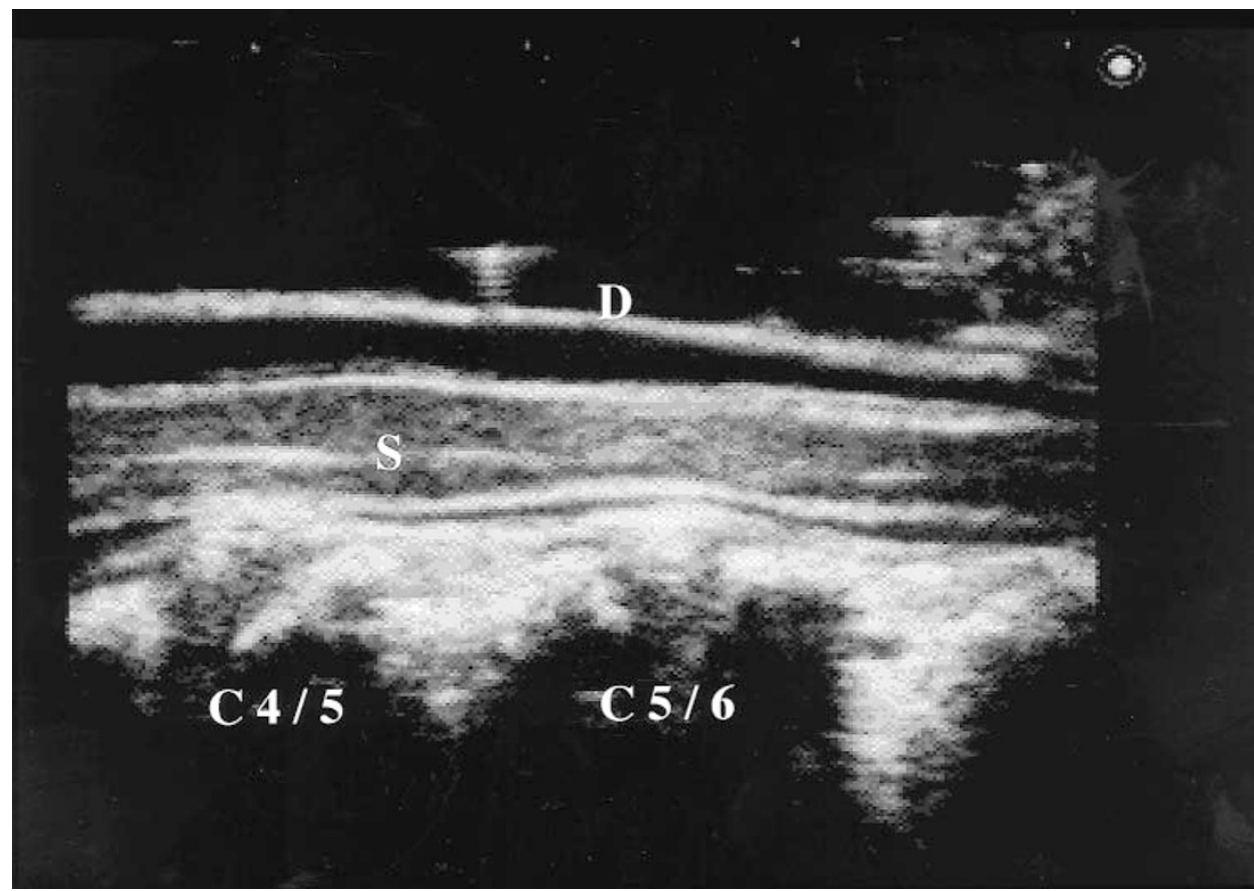

B

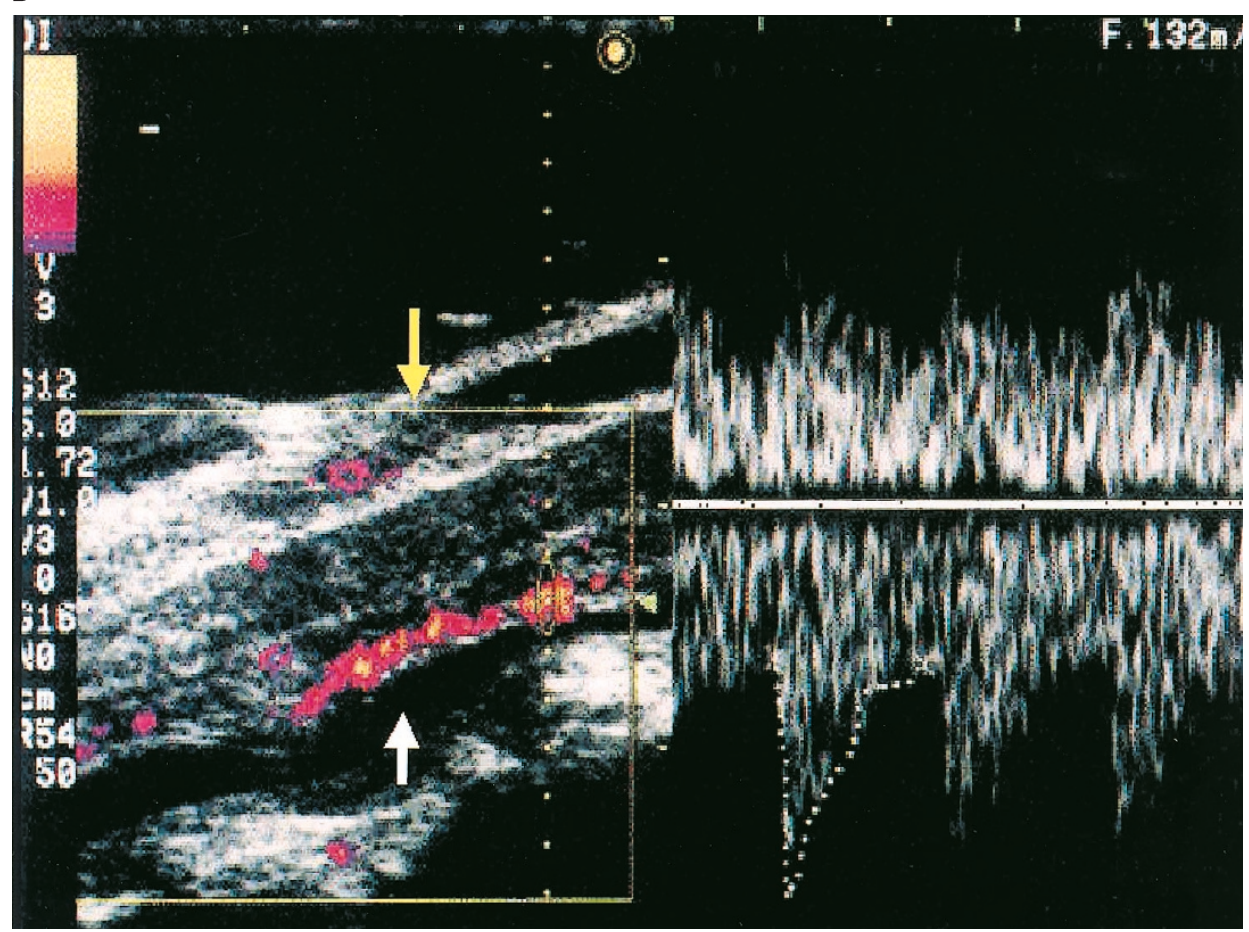

Figure 5 (a) Intraoperative ultrasonography (B-mode). $\mathrm{D}$ =dura mater, $\mathrm{S}$ = spinal cord. (b) Power Doppler ultrasonography. Yellow arrow $=$ dura mater, White arrow $=$ anterior spinal cord artery. Right side shows blood flow (pulse-mode)

mainly by dilating resistance vessels, but it also dilates capacitance vessels at higher doses. ${ }^{3,12}$ At the dose we employed, we speculate that PGE1 dilated resistance vessels and consequently spinal cord blood flow increased despite a reduction in the MAP. PGE1 may also increase tissue blood flow via its anti-platelet effect and inhibition of peripheral sympathetic nerves. $^{18}$ 
In humans, many kinds of prostaglandins (PGs) exist and PGs have many roles. Mathias et $a l^{19}$ reported that plasma prostaglandin $\mathrm{E}$ is released during neurogenic hypertension in tetraplegic men, and hypothesized that PGE may be part of a system involved in blood pressure homeostasis in man. PGE has many roles in humans. There are also several subtypes of PGE. In vivo, PGE2 is produced in greater amounts than PGE1, but PGE1 is a far stronger peripheral vasodilator. ${ }^{20}$ Therefore, PGE1 is used to induce hypotension during anesthesia.

Frankel et $a l^{21}$ reported that cardiovascular change during electrical stimulation was dependent on the degree of lesion in spinal injuries. They also reported that the syndrome of autonomic dysreflexia might occur in patients with high thoracic and cervical cord lesions. In addition, they reported that infusion of PGE2 was effective in reducing hypertension at the time of electric stimulation in these patients. Several authors have reported that PGE1 also enhanced blood flow in the cauda equina. ${ }^{22,23}$ Upon consideration of these facts, we believe that PGE1 may be effective in simultaneously reducing hypertension and restoring spinal blood flow.

In this study, \%PI and \%RI were correlated with age. Okada $e t a l^{24}$ reported that the hypotension effect of PGE1 was more remarkable in the older cases and in the cases who had the more advanced arteriosclerotic change on the ocular fundus. It is known that arteriosclerotic lesion are correlated with age. In consideration of these facts, we suggest that autoregulation of spinal cord blood flow was more maintained on the elderly people. For this reason, we think that PGE1 is an ideal drug for spinal surgery, particularly in older patients.

In conclusion, these results suggest that because it maintains spinal cord blood flow PGE1 may be useful for inducing hypotension during spinal surgery. Moreover, power Doppler ultrasonography is a very useful method for evaluating SBF. The major advantage of this method is its ability to measure the anterior spinal artery directly and rapidly (Figure 5). Previous studies used the heat clearance method, the hydrogen gas clearance method, or a laser-Doppler meter. These methods are unable to measure the anterior spinal artery, which is the major supplier of the spinal cord, and measuring this artery is necessary to evaluate SBF.

\section{References}

1 Fromme GA et al. Controlled hypotension of orthognathic surgery. Anesth Analg 1986; 65: 683-686.
2 Miller Jr ED. Deliberate hypotension. In: Miller RD (ed). Anesthesia. 2nd edn Churchill Livingstone: New York, 1986, $1949-1970$.

3 Abe K, Nishimura M, Kakiuchi M. Spinal cord blood flow during Prostaglandin E1 induced hypotension. Prostagland Leukotrienes Essent Fatty Acids 1994; 51: 173-176.

4 Cottrell JE et al. Intracranial pressure during nitroglycerineinduced hypotension. J Neurosurgery 1990; 53: 309-311.

5 Smith RP, Kruszyna H. Sodium nitroprusside produces cyanide poisoning via a reaction with hemoglobin. J Pharma Exp Ther 1974; 191: $557-563$.

6 Ducker TB, Kindt GW. The vasomotor control of the spinal cord circulation. Proc VA Spinal Cord Int Conf 1969; 17: 69-70.

7 Kobrine AI, Doyle TF, Martins AN. Spinal cord blood flow in the rhesus monkey by the hydrogen clearance method. Surg Neurol 1974; 2: $197-200$

8 Kodama T et al. Measurement of spinal cord blood flow during laminoplasty of cervical spine. Cent Jpn J Orthop Tranmat 1996; 45: 704-706. (in Japanese)

9 Sato $\mathrm{K}$ et al. Intraoperative power Doppler ultrasonography in spinal-cord surgery. J Med Ultrasonics 1997; 24: 973-979. (in Japanese)

10 Hutamura M. Analysis of blood flow signals in ultrasonic Doppler study of gallbladder carcinoma. J Med Ultrasonics 1996; 23: 363 - 372. (in Japanese)

11 Rubin JM et al. Power Doppler US: a potentially useful alternative to mean frequency-based color Doppler US. Radiology 1994; 190: $853-856$.

12 Abe K, Kakiuchi M, Shimada Y. Epidural blood flow during Prostaglandin E1 or trimethaphan induced hypotension. Prostagland Leukotrienes Essent Fatty Acids 1993; 50: 199-202.

13 Silver JR, Buxton PH. Spinal stroke. Brain 1974; 97: 539-550.

14 Turnbull IM. Blood supply of the spinal cord: Normal and pathological considerations. Clin Neurosurg 1973; 20: 56-84.

15 Sekizuka N. Combined examination of middle cerebral artery and umbilical artery flow velocity waveforms in growth-retarded fetuses. Asia-Oceania J Obstet Gynecol 1993; 19: $13-19$.

16 Numata $\mathrm{K}$ et al. Use of hepatia tumor index on color Doppler sonography for differentiating large hepatic tumors. AJR 1997; 168: $991-995$.

17 Dray F, Chrbonnel B, Maclouf F. Radioimmunoassay of prostaglandins F-alpha, E1 and E2 in human plasma. Eur $J$ Clin Invest 1975; 29: $311-318$.

18 Hadhazy P, Vizi ES, Magyar K, Knoll J. Inhibition of adrenoergic neurotransmission by prostaglandin E1 in the rabbit artery. Neuropharmacology 1976; 15: 245-250.

19 Mathas CJ, Hillier K, Frankel HL, Spalding JMK. Plasma prostaglandin $\mathrm{E}$ during neurogenic hypertension in tetraplegic man. Clin Sci Mol Med 1975; 49: 625-628.

20 Eklund B, Carlson LA. Central and peripheral circulatory effects and metabolic effects of different prostaglandins given I.V. to man. Prostaglandins 1980; 20: $333-347$.

21 Frankel HL, Mathias CJ. Severe hypertension in patients with high spinal cord lesions undergoing electro-ejaculationmanagement with prostaglandin E2. Paraplegia 1980; 18: 293 299.

22 Yone K, Sakou T, Kawauchi Y. The effect of Lipo prostaglandin E1 on cauda equina blood flow in patients with lumbar spinal canal stenosis: myeloscopic observation. Spinal Cord 1999; 37: $269-274$.

23 Murakami M et al. Effect of intravenous lipoprostaglandin E1 on neurogenic intermittent claudication. J Spinal Disord 1997; 10: $499-504$.

24 Okada F, Nukada T, Yamauchi Y, Abe H. The hypotensive effect of prostaglandin E1 on hypertensive cases of various types. Prostaglandins 1974; 7: 99-106. 